\title{
ALTERNATIVE METHODS FOR INTERNAL ARC TESTS ON 12 KV AND 24 KV METAL-ENCLOSED SWITCHGEARS WITH COMPACT RMU
}

\author{
George CURCANU, Constantin ILINCA, Ilie SBORA \\ ICMET Craiova, Romania, Calea Bucuresti 144, \\ phone: 40351 402427; +40351 404 888; +40351 404889 \\ fax: +40351 404 890; +40251 415 482; email: $\underline{\text { Imp@icmet.ro }}$
}

\begin{abstract}
Arcing due to an internal arc fault test is carrying out in order to demonstrate the capability of the metal-enclosed switchgear to withstand to stresses generate by electric arc.

Firstly, it is aimed the limitation of the destructive effects of the enclosures and protection of the persons near the metal-enclosed switchgear.

The behaviour of the metal-enclosed switchgear during the test is pointed out by video recordings, which lead to the evaluation of the test result together with the observations stated after test on metal-enclosed switchgear and indicators also.

The paper presents two alternative methods for verification at electric arc action of metal-enclosed switchgears according to international standards.
\end{abstract}

\section{INTRODUCTION}

Stress regimes above normal limits such as overheating and overvoltage can often occur during the functioning of metal - enclosed switchgears. These regimes conduct to a lowering of the insulation resistance of the main circuit components. These effects being cumulative in time, flashovers and breakdowns, which evolve in local or general electric arcing, can occur even for normal stresses [1].

The electric arc occurring develops an energy which in first moments creates an overpressure that stresses the metal - enclosed switchgears structure strength [1].

For strength structure at limit designed, enclosures deformations and even tearing of covers, doors, inspection windows, ventilation openings, etc can occur, sometimes with throwing of these out and flames emissions [1].

Such behaviour, beside the material damages, can lead to operative personnel injuries that are near metal - enclosed switchgears.

In order to limit the destructive effects, a lot of measures are taken starting with the designing phase, so the metal - enclosed switchgears should resist at arcing due to an internal fault.

The proof that the metal - enclosed switchgears fulfil these conditions is checked by laboratory tests.

In this sense, in the paper are presented alternative methods for checking at electric arc on medium voltage metal - enclosed switchgear with compact RMU [2,3].

\section{TESTS AT INTERNAL FAULT}

\subsection{Test conditions}

The tests at internal fault are carrying out on metal enclosed switchgears in similar conditions as in exploitation. As stipulated in IEC 62271-200/2003 standard and technical specification EDF-HN64S52, for metal - enclosed switchgears the test shall be carried out on at least two representative cells which form an assembly.

The test can be carried out on an assembly not previously subjected to arcing, or, if subjected, being in a condition which keep the initial parameters and does not affect the result of the test.

In case of different types of devices that could equip the cell the largest device will be fit in. At the test, the cells shall be fully equipped.

Installation and mounting conditions have to be correctly simulated. The minimum clearance distances in mounting instructions have also to be met, e.g. distance against wall and ceiling, limitation due to covers position and so on.

For the purpose of this test special rooms are used. They are composed of two perpendiculars to each other walls and a ceiling with variable dimensions that can be used for different kinds of cells. The low pressure spaces from outside the cells are also simulated as stated in utilization instructions (e.g. cable ducts and other close units).

In front of accessible parts of the cell, vertical and horizontal indicators (human simulators) are used at a distance of $30 \mathrm{~cm}$ for accessibility type $A$ and $10 \mathrm{~cm}$ for accessibility type B [2].

Vertical indicators have a $2 \mathrm{~m}$ height from the floor and the horizontal ones are placed at a distance of 2 $\mathrm{m}$ from floor and $0.1-0.8 \mathrm{~m}$ around the cell [2].

Both indicators consist of $15 \mathrm{~cm}$ square frames made of textile material with a specific weight of $150 \mathrm{~g} / \mathrm{m}^{2}$ for type A and $40 \mathrm{~g} / \mathrm{m}^{2}$ for type $B$ [2]. The accessibility type is A or B depending of the cells are restricted to authorized personnel only or with unrestricted accessibility, including that of the general public.Example of room simulation with the placement of functional unit and indicators positioning are presented in Figure 1. 


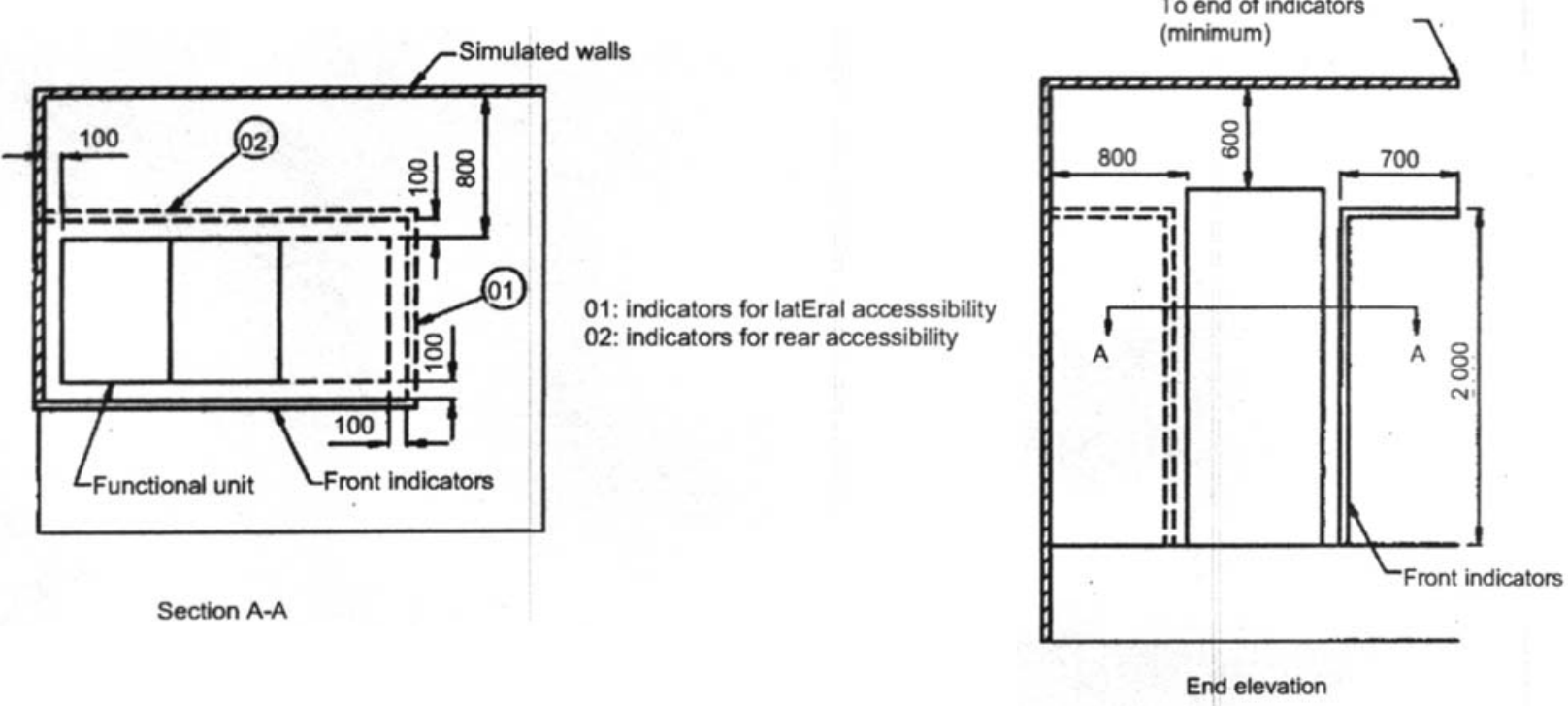

Figure 1 - Room simulation and indicator positioning for accessibility A, functional unit at or above $1.5 \mathrm{~m}$ high

\subsection{Alternative methods for performing internal internal arc test}

Tests at internal arc of metal - enclosed switchgears with compact RMU are applied two alternative methods according to international standards: IEC 62271-200/2003 [2] and technical specification EDFHN64S52 [3]:

- Arc initiation inside of tank by switching failure

- Arc initiation inside of tank by fuse wire inside

\subsubsection{Arc initiation inside of tank by switching failure}

\subsubsection{Test procedure}

The enclosure is filled with low pressure SF6 gas or with atmospheric pressure air in order to have an lower dielectric medium. The electric arc initiated by failure switching which is found in a lower dielectric medium. The procedure is the following: the switch in closed position is passed by inductive load current, adjusted with inductances and resistors (Figure 2) at equal or greater value of rated current, with power factor 0.1 . The arc is initiated by breaking of the switch in the moment when the voltage is applied at switchgear terminals.

If the dielectric medium is not so lower to initiate the electric arc, then the speed of the switchgear is reduced, with an agreement between manufacturer and customer. The homopolar current is limited to 1000 Arms through a resistance coonected on supply neutral earthing. The test are performed in three- phase scheme at $12.5 \mathrm{kArms}$ current with a 5\% tolerance, according to technical specification EDFHN64S52 [3], the test circuit power factor being not higher than 0.15 .

The test voltage is equal or lower to rated voltage of the switchgear, according to reccomendations of international standards $[2,3]$.

\subsubsection{Arc initiation inside of tank by fuse wire inside}

\subsubsection{Test procedure}

The arc shall be generally initiated between all phases by means of a metal wire of about $0.5 \mathrm{~mm}$ in diameter.

The point of initiation, the numbers of tests and the arc supply direction have to assure a maximum stress of the cell. In case of segregated phase conductors, the arc shall be initiated between one phase and earth. The test shall be carried out three phase with a $50 \mathrm{~Hz}$ frequency, the test circuit power factor being not higher than 0.15 .

The applied voltage of the test circuit should be equal to the rated voltage of the metal-enclosed switchgear. A lower voltage may be chosen if the following conditions are met: the arcing current is practically sinusoidal and the arc is not extinguished.

The prospective short-circuit current shall be equal or higher than the thermal rated current (1 s) with a ${ }_{0}^{+} 5 \%$ tolerance and the prospective value of the peak current (flowing in one of outer phases) shall be 2.5 times the r.m.s. value of the a.c. component with a $5 \%$ tolerance. 
The arc duration depends on the making and breaking duration of the protection devices, but not higher than $1 \mathrm{~s}$ for short-circuit currents greater than $25 \mathrm{kArms}$. Above $25 \mathrm{kA}$, the duration has to correspond to functioning conditions of the equipment.

As a synthesis of the two methods, in Table 1 is presented a comparision between the two methods.

Table 1

\begin{tabular}{|l|l|l|}
\hline \multirow{2}{*}{ Parameters/Circuit tests } & \multicolumn{2}{|c|}{ Test methods } \\
\cline { 2 - 3 } & By switching failure & With fuse wire inside \\
\hline Test circuit & $\begin{array}{l}\text { Three-phase with inductive } \\
\text { charging, according to } \\
\text { EDF-HN64S52 }\end{array}$ & $\begin{array}{l}\text { Three-phase without inductive } \\
\text { charging, according to } \\
\text { IEC 62271-200 }\end{array}$ \\
\hline Applied voltage & Equal or lower to rated voltage & Equal or lower to rated voltage \\
\hline Test current & $\mathrm{I}_{\mathrm{T}}=12.5 \mathrm{kArms,}{ }_{0}^{+} 5 \%$ tolerance & $\mathrm{I}_{\mathrm{T}} \leq 40 \mathrm{kArms,}{ }_{0}^{+} 5 \%$ tolerance \\
& $\mathrm{I}_{\text {peak }}=2.5 * \mathrm{I}_{\mathrm{T}},{ }_{0}^{+} 5 \%$ tolerance & $\mathrm{I}_{\text {peak }}=2.5 * \mathrm{I}_{\mathrm{T}},{ }_{0}^{+} 5 \%$ tolerance \\
\hline Charge inductive current & $\begin{array}{l}\text { Equal or higher to operating rated } \\
\text { current }\end{array}$ & - \\
\hline Test duration & $0.7 \mathrm{~s}$ & 0.1 or $0.5 \mathrm{~s}$ or $1 \mathrm{~s}$ \\
\hline Acceptance criteria & $\begin{array}{l}\text { According to IEC 62271-200, } \\
\text { Annex A6 }\end{array}$ & $\begin{array}{l}\text { According to IEC 62271-200, } \\
\text { Annex A6 }\end{array}$ \\
\hline
\end{tabular}

\subsection{Acceptance criteria}

After the test, currents and voltage on arc recordings are checked, observing the sinusoidal shape of the currents, the values of the symmetrical component and the peak current, either the duration of the current which shall be in the specified values.

The indicators (human simulators) are also checked in order to identify the ignitions, if any.

The enclosure state is also checked in order to identify possible deformations, detachments of parts from cells, perforation due to hot gases.

The metal-enclosed switchgear/substation has passed the test successfully if the following criteria are fulfilled:

a. correctly secured doors and covers do not open;

b. no fragmentation of the enclosure, which could represent a danger, occurs, these could be plane parts with large dimensions, or with sharp edges as: eye holes, explosion covers, cover plates etc made of metal or synthetic materials;

c. the arc does not cause holes in the enclosure in the accessible zone, as a result of burning or of other effects;

d. vertical indicators shall not ignite (with the exception of ignitions due to labels or inscriptions burnings);

e. horizontal indicators shall not ignite. If they should start to burn during the test, the assessment criteria may be regarded as having been met if proof is established (by pictures taken with high speed cameras) of the fact that the ignition was caused by glowing particles rather than hot gases;

f. the enclosure remains connected to its earthing point.

After the test, test reports are concluded containing information about producer, test laboratory, test conditions, results and evaluation of the final result which takes into consideration the fulfilling of the criteria above mentioned.

\section{Experiments on metal-enclosed switchgear with compact RMU}

In High Power Laboratory were performed internal arc tests on:

- $24 \mathrm{kV} / 400$ A metal-enclosed switchgear with compact RMU with arc initiation inside of tank by failure switching, according to IEC 62271-200/2003 [2] and EDF-HN64S52 [3]

- $12 \mathrm{kV} / 630$ A metal-enclosed switchgear with compact RMU with arc initiation inside of tank by fuse wire, according to IEC 62271-200/2003 [2]

\subsection{Experiments on 24 kV / 400 A metal-enclosed switchgear with compact RMU}

The tests were performed according to the below program.

Current calibration test was performed at half value of prospective short-circuit current.

The three-phase internal arc test was performed in the following conditions:

- compact RMU was supplied at input terminals at $12 \mathrm{kV}$, through circuit passing the current of 400 A (inductive load, $\cos \varphi=0.1$ ), according to Figure 2 . 
- at breaking operation of the load break switch from middle compartment filled with small pressure of the SF6 gas occurred electrical arc due to failure switching and its duration was limited by circuit breaker at $0.7 \mathrm{~s}$.

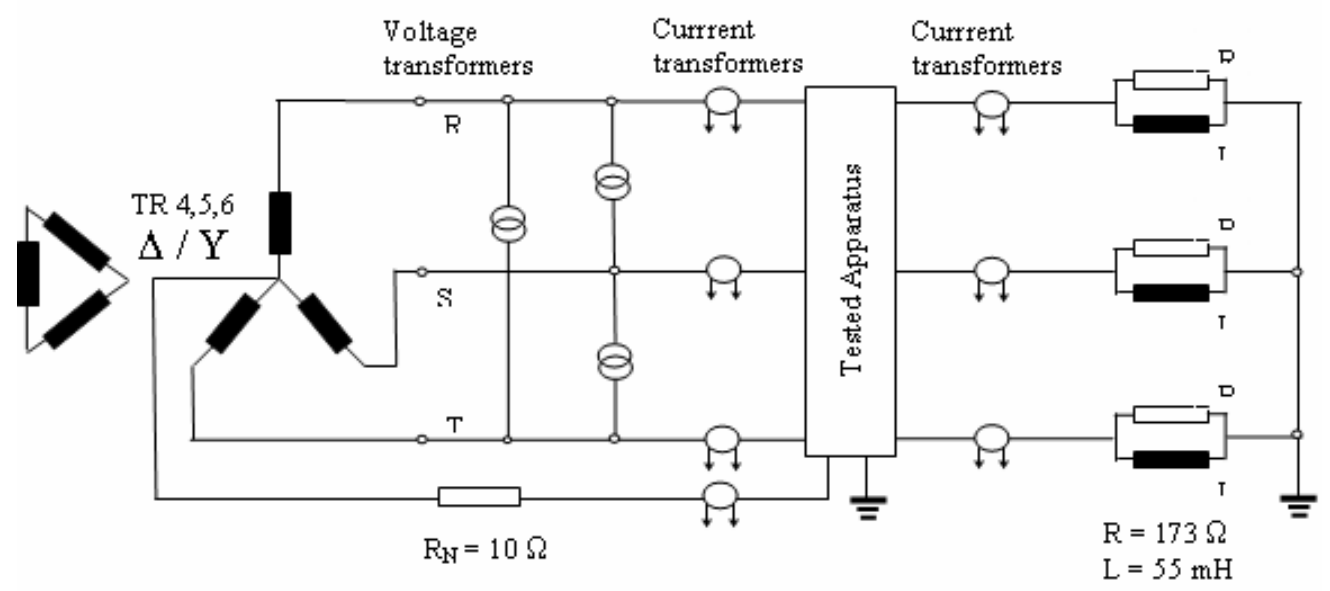

Figure 2 - Circuit with inductive load

The test parameters during the internal test were:

Ip $=31.25 \mathrm{kA}, \mathrm{Ik}=12.5 \mathrm{kA}, \mathrm{tk}=0.7 \mathrm{~s}$ and $12.2 \mathrm{kV}$ three-phase applied voltage on input terminals of RMU.

For the test the RMU was settled on a cable channel with lateral right side open and placed in a special room with two perpendicular walls and ceiling.

The combined vertical and horizontal indicators were mounted in front of the RMU at $300 \mathrm{~mm}$ corresponding to accessibility class A.
The diaphragms for pressure relief located at rear of the RMU opened.

All acceptance criteria were fulfilled.

During the test, oscillograms are recorded showing the currents on all phases $\left(\mathrm{I}_{\mathrm{R}}, \mathrm{I}_{\mathrm{S}}, \mathrm{I}_{\mathrm{T}}\right)$, voltages drop on $\operatorname{arc}\left(\mathrm{DU}_{\mathrm{RS}}, \mathrm{DU}_{\mathrm{ST}}, \mathrm{DU}_{\mathrm{TR}}\right)$ and test duration (Figure 3$)$. Test results are presented in a Test Report [4].

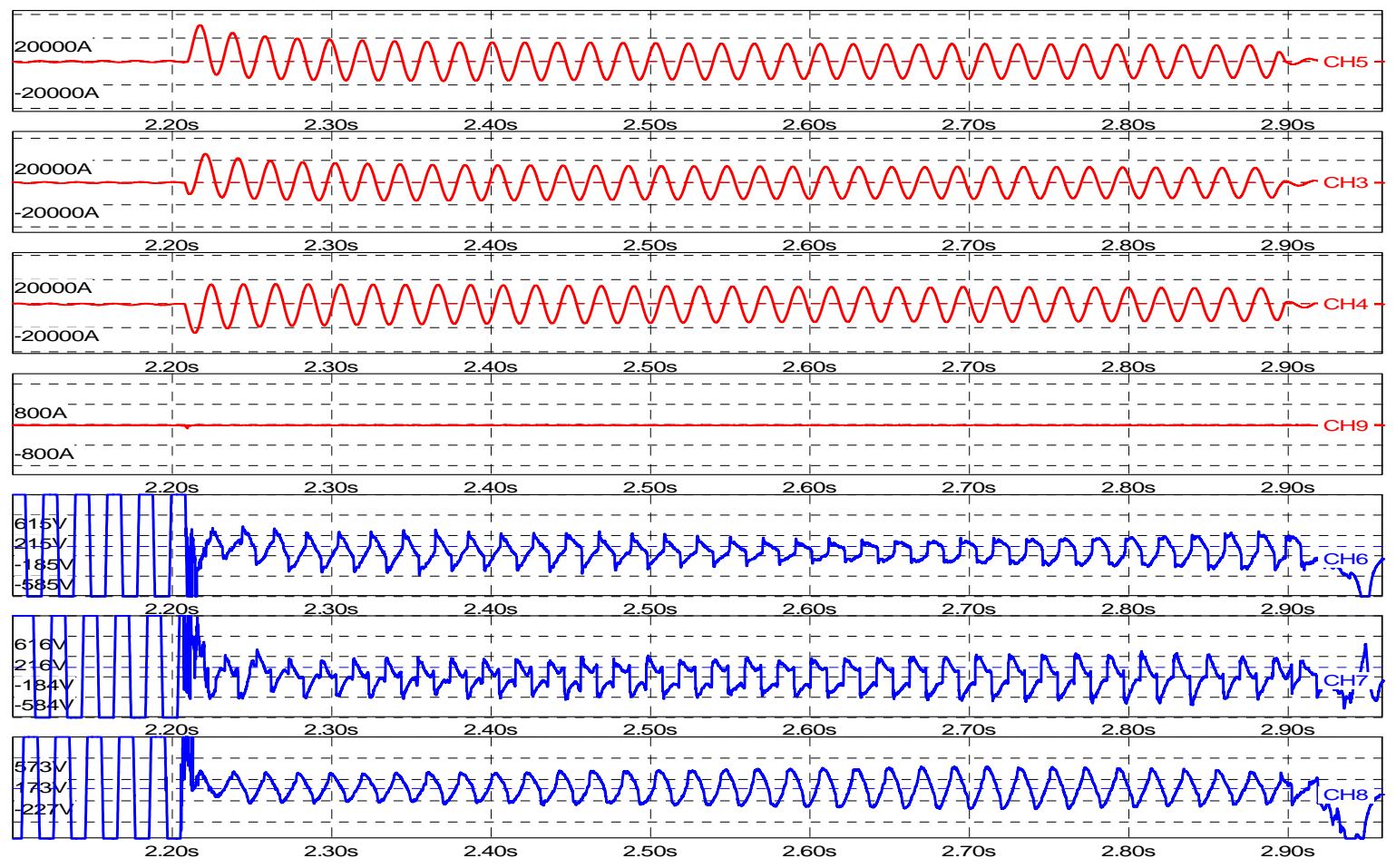

Figure 3 - Oscillogram from internal arc test by switching failure method 


\subsection{Experiments on 12 kV / 630 A metal-enclosed switchgear with compact RMU}

The tests were performed according to the below program.

Current calibration test was performed at half value of prospective short-circuit current.

The three-phase internal arc test was performed in the following conditions:

The internal arc test with three-phase arc initiation inside of tank by means of a cooper wire having $0.5 \mathrm{~mm}$ diameter at parameters: $\mathrm{Ip}=52.5 \mathrm{kA}$, $\mathrm{Ik}=21 \mathrm{kA}, \mathrm{tk}=1 \mathrm{~s}$ and $6 \mathrm{kV}$ three-phase applied voltage on input terminals of RMU.

For the test the RMU was settled on a cable channel with with lateral right side open and placed in a special room with two perpendicular walls and ceiling.

The combined vertical and horizontal indicators were mounted in front and lateral right of the RMU at $300 \mathrm{~mm}$ corresponding to accessibility class A.

The diaphragms for pressure relief located at rear of the RMU opened.

All acceptance criteria were fulfilled.

Test results are presented in a Test Report [5].

\section{CONCLUSIONS}

- Behaviour of the RMU during the internal arc test using both methods: arc initiation by fuse wire and by switching failure was similar.
- It is consider, however that arc initiation by switching failure simulates the real situation which in exploitation can occur.

- High Power Laboratory from Craiova has technical endowment and qualified personnel to perform internal arc tests at short-circuit currents up to $40 \mathrm{kA}$ and $1 \mathrm{~s}$ duration.

- The internal arc tests can be performed in order to develop and verify constructive solutions and to certify the quality of the equipment.

- The Test Reports issued by High Power Laboratory are elaborated according to EN ISO/CEI 17025:2005, and have a harmonious presentation of the tests results so as to be recognized internationally.

\section{REFERENCES:}

[1] Constantin ILINCA, Corneliu CHICIU, Ilie SBORA - The metal - enclosed switchgears and substations behaviour at internal arc fault, Jubillee Symposium, ICMET 2004, Herculane, Romania.

[2] *** - IEC 62271-200:2003 - AC metal-enclosed switchgear and controlgear for rated voltages above $1 \mathrm{kV}$ up to and including $52 \mathrm{kV}$.

[3] *** - Technical specification - AC metal-enclosed equipment EDF-HN64S52.

[4] *** - Test Report No. 9949/20.07.2007

[5] *** -Test Report No. 9948/19.07.2007 